\title{
Changes in breast volume during normal menstrual cycle and after oral contraceptives
}

\author{
D MILLIGAN，J O DRIFE， R V SHORT
}

British Medical fournal, 1975, 4, 494-496

\section{Summary}

The volume of the left and right breasts was measured daily in four nulliparous women during normal menstrual cycles and after the use of oral contraceptives. Breast volume increased significantly in the second half of both normal and contraceptive-controlled cycles. The mean total change in volume throughout the cycle was $100 \mathrm{ml}$ under natural conditions and $66 \mathrm{ml}$ on oral contraceptives.

\section{Introduction}

The human breast seems to be uniquely sensitive to ovarian steroids. Man is the only primate in which gross morphological breast development is completed at puberty; in all other primates the mammary gland develops only as a consequence of the more profound hormonal changes that accompany pregnancy.

Not surprisingly, therefore, many women report breast changes during the normal menstrual cycle, with a feeling of fullness and a tingling sensation immediately before menstruation. ${ }^{1}$ Women taking oral contraceptives also seem to experience similar breast symptoms. ${ }^{2}$ It has been claimed that there are also pronounced changes in breast volume during the normal menstrual cycle, with maximum values occurring in the week before menstruation. ${ }^{3}$ No attempt has been made, however, to study changes in breast volume in women on oral contraceptives. We therefore decided to obtain accurate quantitative information on the nature and extent of breast volume changes in nulliparous women during the course of normal and contraceptive-controlled cycles.

\section{Subjects and methods}

Four healthy nulliparous women, all aged 21 years, were studied for three months.

Case 1 -Before the study this woman had been taking mestranol $50 \mathrm{\mu g}$ plus norethisterone $1 \mathrm{mg}$ (Norinyl 1) daily in 21-day cycles which were each followed by seven tablet-free days. Observations were begun during the second normal cycle ( 21 days) after she had stopped taking the contraceptive. In the next cycle she again took Norinyl 1.

Case 2-This woman had been taking mestranol $50 \mu \mathrm{g}$ plus norethisterone $1 \mathrm{mg}$ (Ortho-Novin 1/50) daily in 21-day cycles (followed by seven days of no treatment), and observations were begun on the sixth cycle. This was followed by a normal ovulatory cycle ( 32 days) and then another contraceptive-controlled cycle.

Case 3-This woman was observed during three consecutive contraceptivecontrolled cycles. She was taking ethinyloestradiol $50 \mathrm{ug}$ plus norethisterone acetate $3 \mathrm{mg}$ (Gynovlar 21) daily in 21-day cycles followed by seven tabletfree days.

Case 4-This woman was not taking oral contraceptives and she was studied for one normal 29-day cycle.

Department of Zoology, University of Edinburgh, Edinburgh D MILLIGAN, BSC, honours student

MRC Unit of Reproductive Biology, Edinburgh EH1 2QW J O DRIFE, BSC, MB, MRC research fellow R V SHORT, FRS, director

These observations provided data on three complete normal cycles and six complete contraceptive-controlled cycles. In one woman (case 2) the occurrence of ovulation during the normal cycle was confirmed by serial progesterone determinations.

Volume measurement technique-A glass mixing bowl 7 inches $(17.8 \mathrm{~cm})$ in diameter standing inside a container on the floor was filled to the brim with water. The woman, kneeling on the floor, lowered one breast into the bowl, thus displacing water into the surrounding container. The volume of water displaced was measured in a 1-litre graduated cylinder. Variability due to postural changes was controlled by marking positions for the container, hands, knees, and elbows on a sheet of plastic. Each woman made three consecutive measurements on each breast every day at the same time, using water of about the same temperature. Repeated measurements were also taken from one woman throughout one day, and the results related to previous posture. A series of consecutive measurements was also made over 40 minutes on the right breast of one woman at water temperature ranging from $45-15 \mathrm{C}$.

\section{Results}

Reliability of technique-A measure of the precision of the technique was obtained from the correlation between measurements made on left and right breasts for each day of the cycle. The correlation coefficient was highly significant $(P<0.001)$ for all individual cycles (table I). The "error" in the method was calculated by expressing the variation between consecutive measurements made on one breast on any one day as a percentage of the total change in volume during the cycle. Table I shows the error for each subject expressed as a coefficient of variation. Results of experiments to show the effects of previous posture and temperature on breast volume are given in tables II and III. There was a significant change in volume with posture $(P<0.001)$ and a significant decrease in volume with decreasing water temperature $(0.05>P>0.02)$.

TABLE I-Correlation between measurements on left and right breasts, showing precision of technique

\begin{tabular}{c|c|c}
\hline Case No & $\begin{array}{c}\text { Correlation coefficient between measurements } \\
\text { on left and right breasts }\end{array}$ & $\begin{array}{c}\text { Overall coefficient } \\
\text { of variation }\end{array}$ \\
\hline 1 & 0.859 & $2 \cdot 1$ \\
2 & 0.728 & $8 \cdot 5$ \\
3 & 0.865 & $3 \cdot 2$ \\
4 & 0.889 & $5 \cdot 4$ \\
\hline
\end{tabular}

TABLE II-Variation in breast volume after consecutive changes in posture

\begin{tabular}{|c|c|c|c|c|c|}
\hline & & \multicolumn{2}{|c|}{ Horizontal for: } & \multicolumn{2}{|c|}{ Vertical for: } \\
\hline & & 4 hours & 11.5 hours & 4 hours & 11.5 hours \\
\hline $\begin{array}{l}\text { Right breast }(\mathrm{ml}) \\
\text { Left breast }(\mathrm{ml})\end{array}$ & $\begin{array}{l}. \\
\therefore\end{array}$ & $\begin{array}{l}523 \\
530\end{array}$ & $\begin{array}{l}552 \\
588\end{array}$ & $\begin{array}{l}532 \\
543\end{array}$ & $\begin{array}{l}562 \\
600\end{array}$ \\
\hline
\end{tabular}

TABLE III-Variation in breast volume with consecutive decreases in water temperature

\begin{tabular}{l|r|r|r|r|r|r|r}
\hline $\begin{array}{l}\text { Temperature (C) } \\
\text { Breast volume (ml) }\end{array}$ & 45 & $\begin{array}{r}40 \\
564\end{array}$ & $\begin{array}{r}35 \\
571\end{array}$ & $\begin{array}{r}30 \\
514\end{array}$ & $\begin{array}{r}25 \\
525\end{array}$ & $\begin{array}{r}20 \\
505\end{array}$ & $\begin{array}{r}15 \\
518\end{array}$ \\
\hline
\end{tabular}

Cyclical changes-Breast volume increased significantly during the second half of normal and contraceptive-controlled menstrual cycles $(P<0.001$; fig 1$)$, although there was no consistent difference in total 
volume change between normal and contraceptive-controlled cycles (figs 2 and 3 ). The pattern of volume change seemed to be different within one woman under different hormonal conditions (see fig 1). In the normal ovulatory cycle the smaller breast volumes were found on days $9-17$, with a steep rise until day 25 and a subsequent gradual

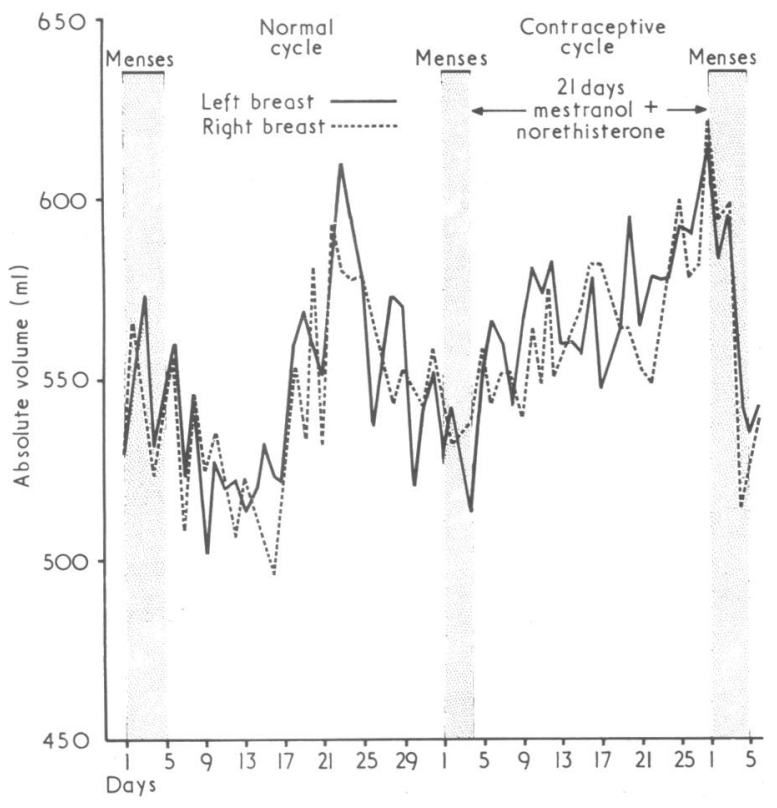

FIG I-Case 2. Absolute volume changes with time throu ghout normal cycle and subsequent contraceptive-controlled cycle.

decrease up to and during the menses. In the contraceptive-controlled cycle breast volumes rose steadily throughout the 21 days of steroid treatment, reaching a peak 4 days after completion of the course and dropping rapidly during the period of withdrawal bleeding.

Although the decrease in breast volume in contraceptive-controlled cycles started on different days in different women, in every case the main decrease occurred during the week when the pill was not taken. Breast volumes increased again with the start of a new course of steroid treatment (fig 3). Minimum volumes occurred about a week earlier in contraceptive-controlled cycles than in normal menstrual cycles. The pattern of breast volume changes in normal cycles (fig 2 ) followed closely the incidence of subjective feelings of tenderness and swelling of the breasts reported by McCance. ${ }^{1}$

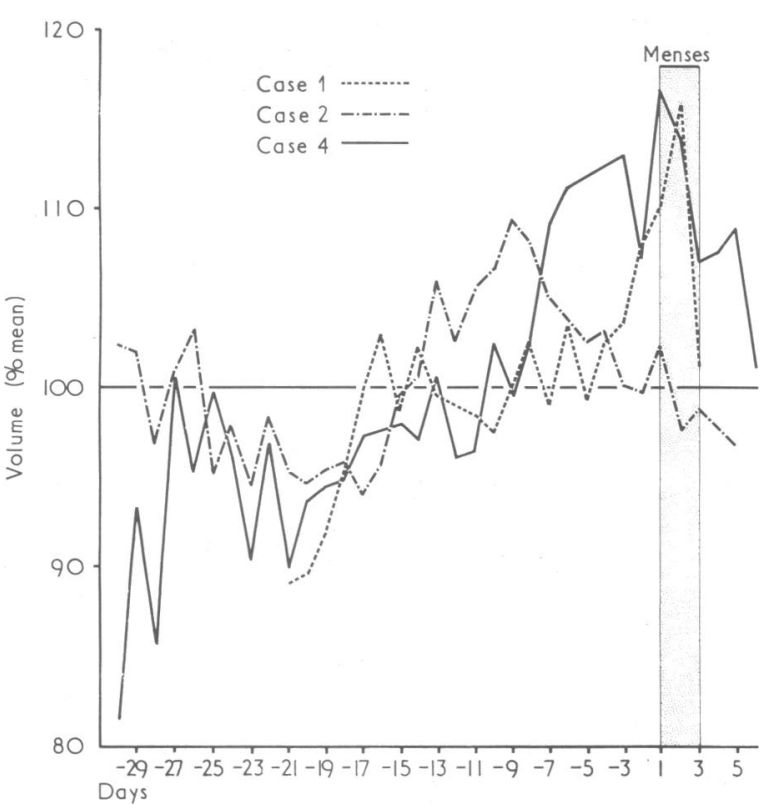

FIG 2-Volume changes throughout all complete normal cycles expressed as percentages of mean volume for each cycle and plotted backwards from first day of menses.
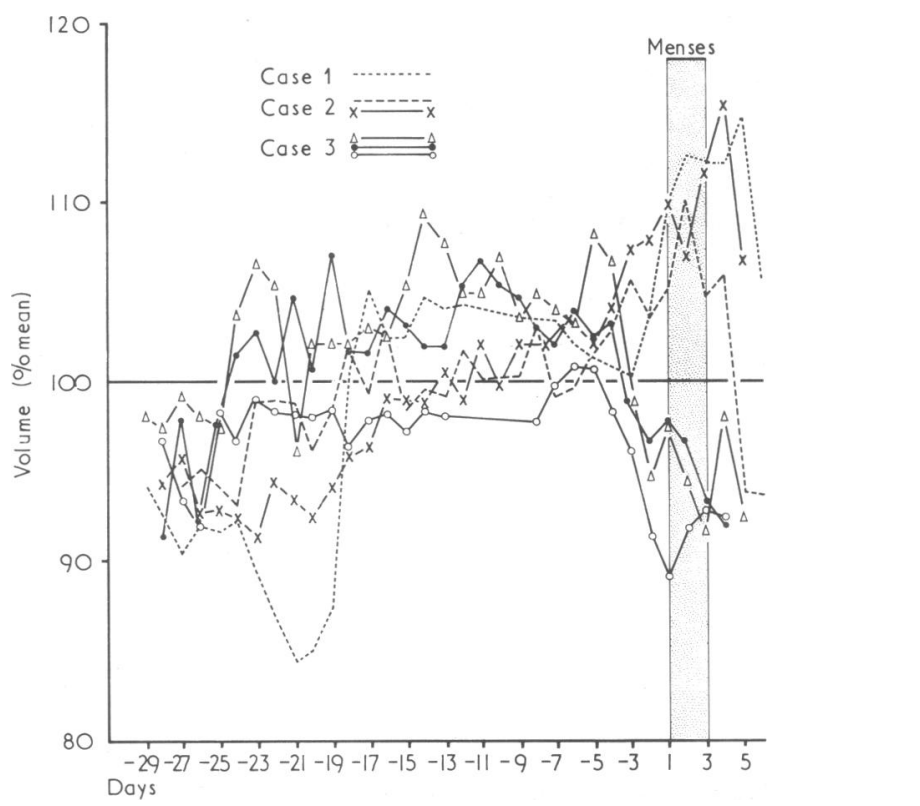

FIG 3-Volume changes throughout all complete contraceptive-controlled cycles expressed as percentages of mean volume for each cycle and plotted backwards from first day of menses.

\section{Discussion}

Others have attempted to measure changes in human breast volume during the normal menstrual cycle by planimetric measurements of breast radiographs ${ }^{4}$ or a water displacement technique. ${ }^{5}$ The most detailed study is that of Ingleby, ${ }^{3}$ who made weekly plaster casts of the breasts and then weighed the wax impressions made from these casts. She found the smallest breast volumes in the follicular plase of the cycle in seven out of nine women, with an $8-44^{\circ}{ }_{0}$ increase above minimum values during the second half of the cycle.

Masters and Johnson ${ }^{6}$ reported a $20-25^{\circ}{ }_{0}$ increase in breast volume during intense sexual excitement, which they attributed to deep vasocongestion; they do not make clear, however, whether these changes were objective measurements or merely subjective assessments. Hytten ${ }^{7}$ measured breast volume changes during pregnancy in 11 women by a water displacement technique. He found that the breasts had often attained their maximum volume by the end of the second trimester. Even in nullipara there was no significant relation between initial breast size and the degree of enlargement, which might exceed $100^{\circ} \%$, but there was a highly significant correlation between the degree of enlargement and the subsequent milk yield.

Our findings confirm and extend these earlier observations on cyclic changes and provide the first information available on the effects of the contraceptive pill. The mean total change in natural cycles was $100 \mathrm{ml}$ while the mean total change for all contraceptive-controlled cycles was $66 \mathrm{ml}$, and the pattern of change during normal and contraceptive-controlled cycles was broadly similar (see figs 2 and 3 ). The high correlation coefficients obtained by each woman for measurements on her left and right breasts gives some indication of the reliability of this technique of measurement.

The fact that a considerable degree of histological ${ }^{8}$ and morphological ${ }^{9}$ breast development occurs in girls before the menarche is perhaps the strongest argument for believing that this development is oestrogen dependent. Subsequent changes in volume during the menstrual cycle might be a result of hormonally controlled vascular and lymphatic changes ${ }^{10}$ or structural changes in the intralobular stroma ${ }^{11}$ and alveolar epithelium ${ }^{21}$. In the rhesus monkey ${ }^{13}$ alveolar and lobular enlargement occurs only in the second half of ovulatory cycles, ${ }^{3}$ which suggests that this is specifically a progestational change. 
There is circumstantial evidence to suggest that a repeated succession of menstrual cycles before the first pregnancy may even be harmful to the breast ${ }^{14}$; recent epidemiological evidence shows that the risk of breast cancer increases with time elapsed from menarche to first pregnancy. ${ }^{1516}$ Such considerations highlight the importance of a fuller understanding of the changes taking place in the breast during the normal menstrual cycle and after the use of oral contraceptives.

We thank those women who generously volunteered to take part in this study and are grateful to Dr C S Corker and Mr R Sharpe for statistical advice.

\section{References}

${ }^{1}$ McCance, R A, Luff, M C, and Widdowson, E E, Fournal of Hygiene, 1937, 37, 571.

${ }^{2}$ Royal College of General Practitioners, Report on Oral Contraceptives and Health. London, Pitman Medical, 1974.
3 Ingleby, H, Bulletin of the International Association of Medical Museums, $1949,29,87$.

${ }^{4}$ Reimann, S P, and Seabold, P S, American fournal of Cancer, 1933, 17, 34.

${ }^{5}$ Geschickter, C F, Diseases of the Breast. Philadelphia, Lippincott, 1945.

${ }^{6}$ Masters, W H, and Johnson, V E, Human Sexual Response. London, Churchill, 1966.

' Hytten, F E, British Medical fournal, 1954, 1, 912

${ }^{8}$ Dawson, E K, Edinburgh Medical fournal, 1934, 41, 653.

${ }^{9}$ Marshall, W A, and Tanner, J M, Archives of Disease in Childhood, 1969, 44, 291.

${ }^{10}$ Haagensen, C D, Diseases of the Breast. London, Saunders, 1956.

11 Ozzello, L, and Speer, F D, American Fourral of Pathology, 1958, 34 (5), 993.

12 Engel, S, Proceedings of the Royal Society of Medicine, 1947, 40, 899.

13 Speert, H, Contributions to Embryology, 1948, 32, 9.

${ }^{14}$ Short, R V, in Physiology and Genetics of Reproduction, part A, ed E M Coutinho and F Fuchs. New York, Plenum, 1974.

${ }^{15}$ MacMahon, B, Cole, P, and Brown, J, Fournal of the National Cancer Institute, 1973, 50, 21.

${ }^{16}$ Shapiro, S, et al, in Host Environment Interactions in the Etiology of Cancer in Man, ed R Doll and I Vodopija, p 169. Lyon, International Agency for Research on Cancer, 1973.

\title{
Histological evidence of carcinoma in a hepatic tumour associated with oral contraceptives
}

\author{
M DAVIS, B PORTMANN, M SEARLE, RALPH WRIGHT, ROGER WILLIAMS
}

British Medical fournal, 1975, 4, 496-498

\section{Summary}

A primary hepatic tumour occurred in a 21-year-old woman who had been taking oral contraceptives for two years; she was treated by partial hepatectomy. Part of the neoplasm showed features suggestive of focal nodular hyperplasia, while the remainder had the histological characteristics of a well-differentiated hepatocellular carcinoma. This is the first report of malignant transformation of a tumour in a patient taking oral contraceptives.

\section{Introduction}

Since 197225 cases of benign primary tumour of the liver have been described in women taking oral contraceptives. ${ }^{1-12} \mathrm{~A}$ particular feature of these neoplasms has been their extreme vascularity, and two-thirds of the patients have presented with haemoperitoneum from spontaneous rupture, which carries a mortality of $60 \%$. We describe here for the first time a further complication of this condition: malignant transformation of the tumour.

\section{Case report}

A 21-year-old woman was found on a routine blood check to be anaemic with a haemoglobin of $9.9 \mathrm{~g} / \mathrm{dl}$ and an erythrocyte sedimentation rate of $100 \mathrm{~mm}$ in one hour (Westergren). Her history was negative except for an attack of acute hepatitis some two years earlier, from which she had made a complete recovery, with return to normal liver function. Hepatitis B surface antigen ( $\mathrm{HBsAg}$ ) had never been found in her serum. She had been taking Volidan (megestrol acetate $4 \mathrm{mg}$, ethinyloestradiol $50 \mathrm{~kg}$ ) for contraception continuously for two years, since her recovery from hepatitis.

Physical examination showed, in addition to the anaemia, firm enlargement of the left lobe of the liver. Liver function tests gave abnormal results, with a serum bilirubin of $20 u \mathrm{~mol} / 1(1.2 \mathrm{mg}$ $100 \mathrm{ml}$ ) and alkaline phosphatase of $244 \mathrm{IU} / \mathrm{l}$. Other investigations, including estimations of immunoglobulins, $\alpha$-fetoprotein, and HBsAg, showed no abnormalities. Coagulation test results were normal except for a slightly prolonged partial thromboplastin time. A technetium liver scan showed a filling defect in the left lobe of the liver, and a selenium scan showed uptake in this area. Hepatic arteriography confirmed the presence of a highly vascular tumour in the left lobe, supplied by the middle and left hepatic arteries. At laparoscopy the left lobe of the liver was diffusely enlarged and somewhat purple.

The patient underwent left hepatectomy on 6 November 1974 and left hospital three weeks later after an uneventful postoperative course. She has since remained well, with no evidence of tumour on serial liver scans.

PATHOLOGICAL APPEARANCES OF RESECTED TUMOUR

The left hepatectomy specimen weighed $820 \mathrm{~g}$ and contained a well-circumscribed multilobular mass $14 \mathrm{~cm}$ in diameter. Some parts of the lobules were light brown, but most of the tumour was grey and more friable. The central part of the mass was occupied by partially calcified fibrous tissue, which radiated between the lobules. Patchy haemorrhages were scattered throughout the mass, but no major haemorrhage was seen.

Microscopic examination showed the whole tumour to be well demarcated from the surrounding liver tissue, which was histologically normal except for mild portal tract inflammation, although a true capsule was not present. The light brown areas of the tumour were composed of liver cells that appeared fairly normal, although rather 